\section{Spondyloarthritis in African Blacks}

\section{To the Editor:}

Psoriatic arthritis (PsA) appears extremely rarely in African black populations $^{1,2}$. To the best of our knowledge, no population-based data are currently available on the prevalence and incidence of PsA in the African black population in sub-Saharan Africa, including South Africa. In South Africa, hospital-based prevalence studies, almost all of which are done in dermatology departments, show the prevalence of psoriasis to be about $2.8 \%$ to $3.5 \%$ in whites ${ }^{3}$. These figures are similar to those shown in other parts of the world ${ }^{4}$. In a study undertaken in 5 academic hospitals serving the public sector in Johannesburg, 5355 consecutive African black patients with dermatological problems were assessed, of which $112(2.1 \%)$ had psoriasis ${ }^{3}$.

We report the complete absence of African black patients with PsA and ankylosing spondylitis (AS) at the Rheumatology Clinic, Prince Mshiyeni Memorial Hospital, Durban, South Africa, over a 5-year period between January 2007 and December 2011. This was first noted in a cross-sectional survey of 1352 South African blacks in a study in $1975^{5}$. In more recent reviews of the subject, similar findings were found from other parts of Africa ${ }^{6,7}$

Of the 288 consecutive patients with PsA, 192 were South Africans of Indian descent, 94 were South Africans of European descent, and 2 were of mixed race. Only patients who fulfilled the ClASsification for Psoriatic ARthritis (CASPAR) criteria for a diagnosis of PsA were included in the study ${ }^{8}$. There were no South African black patients with PsA documented in our cohort (Figure 1). Of the 288 patients with PsA, 167 were men and 121 were women. Mean age was 51 years (range 20-83 yrs). Mean duration of arthritis before diagnosis was 11.3 months (range 3-226 mos).

There were 248 patients with AS who fulfilled the modified New York criteria for the diagnosis of $\mathrm{AS}^{9}$. There were 184 whites and 64 patients of Indian origin. There were no African black patients or patients of mixed race with AS in our cohort.

Apart from PsA, no African black patients were seen in our cohort of 248 patients with AS. This probably represents the low prevalence of HLA-B27 positivity among African blacks ${ }^{7,10}$. A fair number of patients (51) with human immunodeficiency virus (HIV)-related rheumatological problems were seen; however, none of these patients had psoriasis/PsA or AS.

A limitation of our study could be bias by inadequate healthcare service access by the general population. It should be noted, however, that we did see African black patients with rheumatoid arthritis, osteoarthritis, and

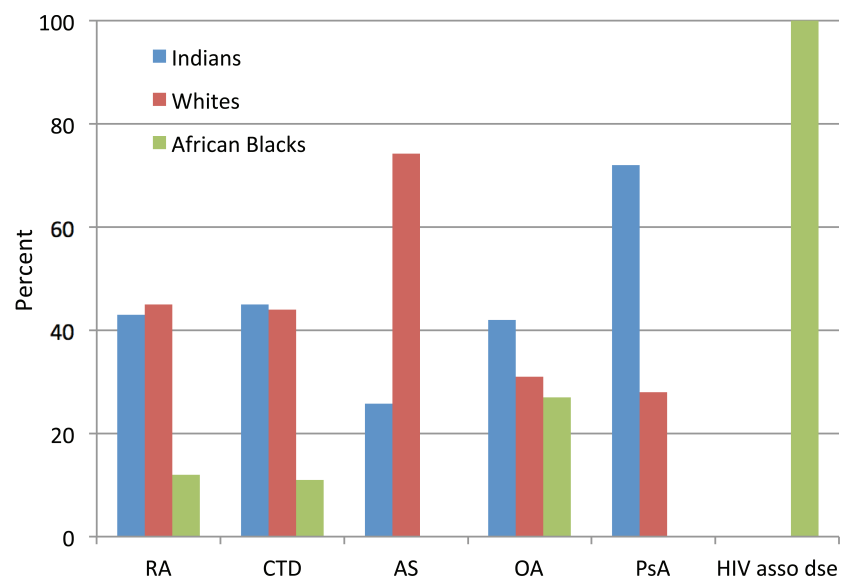

Figure 1. The racial breakdown of the various rheumatic diseases in South African populations (\%) seen at our clinic. RA: rheumatoid arthritis; CTD: connective tissue diseases; AS: ankylosing spondylitis; OA: osteoarthritis; PsA: psoriatic arthritis; HIV asso dse: human immunodeficiency virus-associated rheumatological diseases.
HIV-associated musculoskeletal disease in our clinic. Taken together, the results suggest that PsA and AS may be very rare in African black patients. Our work provides the rationale for further work in independent cohorts, and if confirmed, research on risk and protective factors in African black populations to better delineate the importance of genetic and environmental factors in the pathogenesis of PsA and AS.

AJESH B. MAHARAJ, MB, BS, IMS, BHU (Varanasi), H Dip Int Med (SA), FCP(SA), Certificate in Rheumatology (SA), Prince Mshiyeni Memorial Hospital, Nelson R. Mandela School of Medicine, University of KwaZulu Natal, Durban, South Africa, and the Division of Clinical Immunology and Rheumatology, Academic Medical Center/University of Amsterdam, Amsterdam, the Netherlands; PAUL P. TAK, MD, PhD (UvA), Division of Clinical Immunology and Rheumatology, Academic Medical Center/University of Amsterdam, Amsterdam, the Netherlands. Address correspondence to Dr. A.B. Maharaj, Academic Medical Center, Immunology and Rheumatology, University of Amsterdam, Amsterdam, 1100 DD, the Netherlands. E-mail: maharaja30@ukzn.ac.za

\section{REFERENCES}

1. Namazi MR. Why is psoriasis uncommon in Africans? The influence of dietary factors on the expression of psoriasis. Int $\mathrm{J}$ Dermatol 2004;43:391-2.

2. Leder RO, Faber EM. The variable incidence of psoriasis in sub Saharan Africa. Int J Dermatol 1997;36:911-9.

3. Hartshorne ST. Dermatological disorders in Johannesburg, South Africa. Clin Exp Dermatol 2003;28:661-5.

4. Chandran V, Raychaudhuri SP. Geoepidemiology and environmental factors of psoriasis and psoriatic arthritis. J Autoimmun 2010;34:J314-21 .

5. Solomon L, Beighton P, Valkenburg HA, Robin G, Soskolne CL. Rheumatic disorders in the South African Negro. Part I. Rheumatoid arthritis and ankylosing spondylitis. S Afr Med J 1975;49:1292-6.

6. Tikly M, Njobvu P, McGill P. Spondyloarthritis in sub-Saharan Africa. Curr Rheumatol Rep 2014;16:421.

7. Mijiyawa M, Oniankitan O, Khan MA. Spondyloarthropathies in sub-Saharan Africa. Curr Opin Rheumatol 2000;12:281-6.

8. Taylor W, Gladman D, Helliwell P, Marchesoni A, Mease P, Mielants H; CASPAR Study Group. Classification criteria for psoriatic arthritis: development of new criteria from a large international study. Arthritis Rheum 2006;54:2665-73.

9. van der Linden S, Valkenburg H, Cats A. Evaluation of diagnostic criteria for ankylosing spondylitis. A proposal for modification of the New York criteria. Arthritis Rheum 1984;27:361-8.

10. Khan MA. HLA-B27 and its subtypes in world populations. Curr Opin Rheumatol 1995;7:263-9.

J Rheumatol 2015;42:1; doi:10.3899/jrheum.141023 